\title{
Twins Are Always Serving Science, What About Their Own Needs? Twins' Need for Social Anxiety Program
}

\author{
Sule Bastemur ${ }^{1} \&$ Ayse Esra Aslan ${ }^{2}$ \\ ${ }^{1}$ School of Education, Ordu University, Ordu, Turkey \\ ${ }^{2}$ School of Education, Istanbul University-Cerrahpasa, Istanbul, Turkey \\ Correspondence: Sule Bastemur, School of Education, Ordu University, Ordu, Turkey. E-mail: \\ sulebastemur@odu.edu.tr \\ Received: June 20, $2021 \quad$ Accepted: July 22, $2021 \quad$ Online Published: July 29, 2021 \\ doi:10.5539/jel.v10n5p1 URL: https://doi.org/10.5539/jel.v10n5p1
}

\begin{abstract}
Objective: The effectiveness of the Social Anxiety Program on Adolescent Twins investigated in this study. Method: The study is a mixed-method study using a one-group pretest-posttest design, together with the qualitative method. First, Intraclass Correlation Coefficient used to find out the concordance and differentiation level of the twins' social anxiety. Because monozygotic twins' concordance rate is higher than dizygotic twins, four pair female monozygotic twins aged 17-18 participated in the group. Wilcoxon Single Ranks Test used to analyze the experimental part of the research. Three sessions of focus groups held after the program. Content analysis techniques used as a qualitative analysis. Result: As a result, there was a statistically significant difference between pre/post-program. Since this difference was in favor of initial measurement, the program interpreted as being effective. Themes also supported the quantitative results. Conclusion: Findings obtained from both experimental and qualitative parts discussed. Suggestions provided for future researcher.
\end{abstract}

Keywords: monozygotic twins, dizygotic twins, social anxiety, adolescents

\section{Introduction}

\subsection{Introduce the Problem}

Twin adolescents have different emotional needs than singletons and they may have troubles that make development difficult for them (Sandbank, 2006a). One of these troubles is associated with socio-emotional problems, which is one of the problems that twins frequently face (Klein, 2012). While adolescents constitute the group that is most at risk of social anxiety (Kessler et al., 2005), being a twin further increases the risk of experiencing social problems (Ainslie, 1997). One of the main reasons for this is the genetic dimension of social anxiety in the developmental framework (Torvik et al., 2016), while another reason is the different socialization processes that are true for twins (Lytton, 1980). When these differences in twins combine with other problems that appear during adolescence, which are assessed as one of the most difficult developmental stages, it is not surprising to come across problems related to social anxiety.

Twins have different reasons for having social anxiety. The leading points among these reasons are family (parents that have difficulty in reaching an agreement on important decisions during child-raising), personality traits, and fear of negative evaluation which are common among twins as well as singletons, while socialization processes and ultimate closeness between twins are causes of social anxiety specific to twins. Genetics is another common element, which is a variable found at different dimensions in singletons and twins. As this study only focuses on twins, the causes associated with social anxiety in twins were investigated.

In recent years, research about twins has supported the genetic transfer of social anxiety. Researches have investigated monozygotic (MZ) twins' experience of social anxiety and compared both MZ with dizygotic (DZ) twins. According to research into the hereditary structure of social anxiety, MZ twins have more matches for social fears and shyness when compared to DZ twins (Torgersen, 1979). In situations where social anxiety is observed in one twin, the possibility of observing social anxiety in the other twin increases (Fyer et al., 1993; Kendler et al., 2001; Middeldorp et al., 2005). Moreover, social anxiety symptoms are experienced more by $\mathrm{MZ}$ twins compared to DZ twins (Warren et al., 1999) and social anxiety is moderately affected by genetic factors (Hettema et al., 2005). This situation is supported by research conducted with other family members. 
According to studies about the familial transition of social anxiety, people with a first-degree relative that has social anxiety problem have an increased risk of experiencing social anxiety themselves (Fyer et al., 1993). This finding is evaluated as social anxiety being seen in more than one person in the family at the same time (Mannuzza et al., 1995; Stein \& Chavira, 1998). According to some other research, there is a high correlation between fear of negative evaluation and social anxiety (Leary \& Kowalski, 1995). It is stated that fear of negative evaluation constitutes the core of social anxiety (Turner et al., 1992). In fact, in the social anxiety cognitive model, when others carefully look at people with a high level of fear of negative evaluation, they feel threatened, and if this goes on, it leads to thoughts about rejection or loss of status (Stopa \& Clark, 2000). This results in avoiding social environments. A study with this aim found out that $48 \%$ of fear of negative evaluation is genetic (Stein et al., 2002). This situation supports the genetic structure of fears constituting the basis of social anxiety.

Though the socialization processes can be directly explained by familial factors, the socialization processes for twins are different from singletons and this situation is thought to be directly associated with, the approach of parents to raising twins (Sandbank, 2006b). Such an approach is shown as a socioemotional cause that spurs social anxiety. Twins thought to have lower social skills than singletons (Stewart, 2000). The main reason for this is the 'ultimate closeness' between twins (Klein, 2003). Starting from an early period, twins tend to spend time with their twin pairs rather than with their peers (Hay, 2006). In this case, twins feel socially comfortable when accompanied by their twin pair; however, it may result in experiencing anxiety when the twins are separate. Additionally, attracting more attention as twins in society may cause more anxiety in social environments (Ainslie, 1997). The definition of social anxiety includes the statement of a clear and continuous feeling of fear in cases of meeting unknown people or being looked at by people in society (DSM-V, 2013). As a result, the attention paid to twins in society may be triggering anxiety. This situation may also bring social-based problems.

\subsection{The Aim of the Study}

While being a twin is an advantage at many points, twins are in a more disadvantaged group than singles at some points. Being a twin is considered an advantage in the context of smoking and alcohol abuse, which are more common in adolescence. There is a finding in the literature that twin adolescents are healthier than single adolescents because they abuse fewer cigarettes and alcohol and are more physically active (Cooper, 2004). On the other hand, adolescent twins are seen as a disadvantaged group in terms of socialization and social anxiety. In the context of social anxiety, the disadvantaged group of twins is related to the fact that they feel more comfortable socially when their twin pair is with them and they experience social anxiety-based problems when their twins are separated (Ainslie, 1997). For this reason, there are many unanswered questions about social anxiety in twins. It can be said that (1) adolescent twins experience problems related to social anxiety, (2) these problems are supported by the genetic structure, (3) different from singletons, the ultimate closeness between twins during socialization processes plays an increasing role in social anxiety among twins and (4) social anxiety has severe effects on the development of twins. Based on available research, social anxiety often emerges during singleton adolescence and there is a need to carry out more research with twins. Additionally, there is a need for intervention programs that address social anxiety in twins

According to Novotny (1994), though twins constitute a group that always serves science, science rarely serves twins. Twins serve science through investigation of genetic or environmental factors in behavioral genetic research of certain diseases or traits; however, the psychopathologies, as well as the development and socialization processes of twins, remain in the background. Research about social anxiety problems, frequently observed in twins especially, is not common. As a result, this study aims at reducing the social anxiety of twins with an intervention program for social anxiety. In fact, when social anxiety treatment examines, group-based cognitive-behavioral interventions come to the fore.

\subsection{Development Process for the Intervention Program}

When approaches to social anxiety are considered, it is clear that the cognitive-behavioral approach occupies an important position (Rheingold et al., 2003). According to the cognitive model, a person wishes to create positive impressions on others; however, when one encounters an avoided social situation, mental schemes (incorrect information processing, cognitive distortion, and negative automatic thoughts) come into play and signal that the person is in danger (Beck \& Emery, 2015). While individuals attempt to create a positive impression in their environment, social anxiety triggered by the development of thoughts about how it has or will have negative outcomes (Leary \& Kowalski, 1995). At this point, negative automatic thinking and dysfunctional beliefs and thoughts gained from previous experience come into play and cognitive processes intervene (Hofman, 2007). Thus, these individuals lose their ability to intervene and cannot control the danger at the point where anxiety is 
experienced. Though what individuals create in their head due to their negative thoughts about themselves does not actually occur (Stopa \& Clark, 2000), they think that it is real (Beck \& Emery, 2015) and they make predictions that their behavior in social environments will be shameful (Hofmann, 2007). In parallel with this thought, they think that others will evaluate negatively (Rapee \& Heimberg, 1997). This paradoxically developed social anxiety in individuals results in a decrease in social success and further increases social anxiety levels, which destroy the individuals' social performance, eventually causing a vicious cycle (Stopa \& Clark, 2000).

There are three general components in this vicious cycle. Firstly, the individuals build up fearful anticipation, which puts forward that they will fall into shameful situations in social environments. Later, they display avoiding behavior and do not approach the feared situations. Finally, they make negative references to themselves and feel flawed since birth. All of these components experienced by an individual are thought to be associated with cognitive distortion, negative automatic thinking, and dysfunctional attitudes (Smith et al., 2006).

Cognitive therapies think that individuals' perception of danger in a social environment creates and sustains social anxiety, which in turn causes incorrect information processing, cognitive distortions, and negative automatic thinking. In cognitive therapies, they are brought into view, and as a result, automatic thoughts are replaced by functional thinking via the treatment process. Much research in the literature has treated social anxiety both individually and in groups (Butler et al., 2006; Cox et al., 2009; Çakır, 2010; Dugas et al., 2003; Heimberg et al., 1993; Heimberg et al., 1998; Hope et al., 2010; Mcdougall, 1999; Mörtberg et al., 2006; Sayan, 2005; Sertelin-Mercan, 2007; Şimşek, 2011; Van Dam-Baggen \& Kraaimaat, 2000). Considering the effective use of time in-group psychological counseling, the facts that peer support may provide in a group and the group is a small sample of society, groups provide the clients with the advantage of a real possibility to rehearse life (Andrews et al., 2003).

The general aims of the program are ensuring that twin individuals get to know and understand themselves, their twin and other group members, to gain information about social anxiety, to identify situations causing social anxiety in themselves and the responses of their bodies in these situations, to realize that they are not the only ones who suffer from anxiety in social relationships with their twins and others but other individuals may be feeling these anxieties, as well, to become aware of automatic thoughts triggering experiences of social anxiety, to change basic negative beliefs about social anxiety, to identify irrational thoughts, intervene with these thoughts and replace them with logical thinking to overcome the anxiety that they feel in social environments, to gain assertive behavior skills to show appropriate social skills in social environments. Within the framework of the program having such aims, individualization was ensured by having the participants perform activities that would encourage them to be aware of various aspects of being a twin that trigger social anxiety and that would let them experience a healthy differentiation integration process about social problems that they face due to their relationship with their twin. In the light of these aims, the factor of being a twin is emphasized at several points. The researchers developed all activities related to being twins. Several activities were performed about thoughts of twins about being twins, and the effect of being a twin on social anxiety. Each session definitely included ice-breaking activities and the activities mainly focused on the concept of being twins.

Sessions were designed as, meeting and recognizing social anxiety (first session), noticing the changes that occur in their bodies during social anxiety (second session), knowing and reminding of helpful clues in social communication (third session), recognizing emotions and giving appropriate emotional reactions in the face of situations (fourth session) being able to recognize negative automatic thoughts and systematic thinking errors that have an effect on their social anxiety (fifth session), replacing negative automatic thoughts that have an effect on their social anxiety with real and effective thoughts (sixth session), recognizing dysfunctional basic beliefs about social anxiety and replacing them with functional ones (seventh session), recognizing their self-concepts, defining roles in their lives, recognizing their perceptions of themselves, developing positive self-esteem (eighth session), learning assertiveness skills (ninth session), in addition to assertiveness skills, learning behaviors such as thanking, apologizing, responding to admiration, being open to criticism (tenth session),planning to use appropriate behaviors to cope with anxiety (eleventh session), to end and to say goodbye (twelfth session).

\section{Method}

\subsection{Research Design}

This study is a sequential explanatory mixed-method study using a one-group pretest-posttest design as an experimental design, together with the qualitative method. During the first stage of the study, Social Anxiety Program on Adolescent Twins was implemented. After this program was completed, focus group interviews 
were conducted in the second stage of the study. The program implemented only to one group, with no control group used. According to the principle of pragmatism in the field of psychological counseling and guidance (Heppner et al., 2008), it is ethically important and necessary to provide mental health services to all who need them, instead of one group. The qualitative design of the study was conducted as focus group interviews, which have three sessions after the program finished.

\subsection{Participant}

Adolescents to be included in the study group were determined using the 'criterion sampling' method. Within the scope of this study, the first criterion to decide on the adolescents to be included in the study group was being a twin, and the second criterion was the scale applied to both twins. The criteria related to MZ or DZ twins or the gender of twins did not consider within the framework of this study. 17-18 years old 30 pairs reached. All twins are students in grades 11 and 12. The parents of all twins are married. All twins have between 2-6 siblings. All twins live on the east side of the country. Perceived family socioeconomic status is high in one pair and middle in the other twins.

To decide whether to include MZ or DZ twins in the study group, scores are taken from a scale compared between MZ and DZ twins. At this point, Intraclass Correlation Coefficient (ICC) method, which is frequently used in twin research (like IQ and personality), is used. ICC is the 'assessment of compliance between repeated measurements in the same subject or measurement of two or more observations in the same subject" (Ateş, et al., 2009). It is a method especially used for the evaluation of interobserver or intraobserver compliance. ICC is a variance analysis. For the determination of the source of variance and type of effect, different calculation models were used in this analysis. In this research, the 'two-way random effect' model was used (Can, 2016). This model is used in situations with changes sourced in the observer. As the effect of the observer is random, this model was used in this study. Another important point for ICC is whether calculations will be made because of a single measurement or several measurements. At this point, the term 'consistency' is used in this study. Consistency was used to investigate the correlation between the scores obtained from the scale by twin pairs. The intraclass correlation coefficients showed in Table 1 below.

Table 1. Interclass correlation coefficients for Liebowitz subscales for MZ and DZ twins

\begin{tabular}{lllllll}
\hline Liebowitz subscales & \multicolumn{2}{l}{ MZ twins } & \multicolumn{5}{l}{ DZ twins } \\
\cline { 2 - 7 } & $\mathrm{N}$ & $\mathrm{r}$ & $\mathrm{p}$ & $\mathrm{N}$ & $\mathrm{r}$ & $\mathrm{p}$ \\
\hline Avoiding & 15 & .654 & .000 & 15 & .422 & .009 \\
Anxious & 15 & .582 & .000 & 15 & .409 & .011 \\
\hline
\end{tabular}

Though a statistically significant intraclass correlation coefficient at high levels was obtained by MZ twins for avoiding subscale scores $(\mathrm{r}=0.65, \mathrm{p}<0.05)$, a moderate level of statistically significant intraclass correlation coefficient was obtained for DZ twins $(\mathrm{r}=0.42, \mathrm{p}<0.05)$. This means that in social environments, MZ twins display higher consistency with avoiding behavior than DZ twins. Consistency is also present for DZ twins, but it is higher for $\mathrm{MZ}$ twins. For the anxious subscale scores, $\mathrm{MZ}$ twins obtained a moderate level of statistically significant intraclass correlation coefficient $(\mathrm{r}=0.58, \mathrm{p}<0.05)$, while $\mathrm{DZ}$ twins obtained a moderate level statistically significant intraclass correlation coefficient $(\mathrm{r}=0.41, \mathrm{p}<0.05)$. This means that in the context of anxiety felt in social environments, both $\mathrm{MZ}$ and $\mathrm{DZ}$ twins had similar levels of compliance among their own twin types; however, the intraclass correlation coefficient for MZ twins was higher. As a result, the experimental part of the study included MZ twins.

The descriptive values for measurements related to the Liebowitz Social Anxiety Scale (LSAS) applied to twin groups during the determination of the study group showed in Table 2 below.

Table 2. Descriptive Values for Social Anxiety Scores in the Study Group

\begin{tabular}{llll}
\hline & $\mathrm{N}$ & $M$ & $S d$ \\
\hline Anxiety scores & 60 & 54.14 & 23.12 \\
\hline
\end{tabular}

As is seen in the table, the mean social anxiety for adolescent twins was calculated with the SPSS 22 program (IBM Corp., 2013), and mean ( $\mathrm{M}=54.14)$ and standard deviation $(\mathrm{Sd}=23.12)$ were specified. Twins with social anxiety scores below the mean excluded from the study even if their twin pair was above the mean and 12 pairs 
of MZ and DZ twins obtained social anxiety scores above the mean. Six of these 12 pairs were excluded from the study, as they were DZ twins. The remaining six pairs of twins and their parents were interviewed about participating in the study. Of these adolescents, four MZ twin pairs agreed to participate in the study.

\subsection{Data Collection Tools}

Leibowitz Social Anxiety Scale has two subscales, which are 'fearful or anxious' and 'avoiding' behavior. The total scores that can be obtained vary from 0 to 144, with scores for each subscale from 0 to 72 . Dilbaz (2001) conducted validity and reliability test for the LSAS in Turkish culture. The scale has high internal consistency scores $(\alpha=.98)$. In addition, according to variance analysis and discriminant analysis, the scale differentiates individuals with social anxiety diagnoses from other individuals or individuals with a different diagnosis. The responses given to the LSAS had a Cronbach alpha value of $\alpha=.93$. This value was $\alpha=.89$ for the fearful/anxious subscale and the reliability coefficient for the avoiding subscale was $\alpha=.88$.

\subsection{Procedure}

The experimental part of the study carried out once a week in the group counseling office of the psychological counseling and guidance center of a school that chooses previously for this study. The total number of sessions is 12. The counselors determined the most suitable hours and days for the participant adolescent twins. The program lasted for 120 minutes on average.

The researchers following the Cognitive Behavioral Model developed the program used in the study. Both researchers are cognitive-behavioral psychological counselors and works on social anxiety problems for many years. The program is unique because specifically developed for twins, whose needs are often overlooked in the counseling field. When the program was completed, three academics who were experts in their fields (one program developer in education and psychology, one counseling psychologist who is a mother of twins, and one psychologist who is MZ twin) asked to give their opinions on the applicability of the program. The program was revised and applied after receiving the feedbacks of these academics.

The qualitative part of the research started the week after the experimental part was completed, and held in 3 sessions. Each session lasted for an average of 45-60 minutes and they all planned as a focus group interview. According to Krueger (1994), focus group interviews are a carefully planned discussion in an environment where individuals can freely express their thoughts. Ten questions involving social anxiety directed to participants in focus group interviews and they were requested to express their ideas about these questions. The questions that were asked to the participants aimed at gaining information about the symptoms of social anxiety that they had before focusing group interviews; about their beliefs, thoughts, and feelings as to whether being a twin increases social anxiety or not, or about their beliefs, thoughts, and feelings that increase or decrease social anxiety; about their parents' attitudes (that aggravated social anxiety) as to their socialization starting from their childhood; about the effects of their wishes to be at the same school, even in the same class throughout their educational life; about the effects of being a twin on making friends or socialization in general; about the results of being a twin with a high level of social anxiety; about the changes they felt about themselves after the group work and about the effects of group work on their communication with their twins.

\subsection{Ethical Issues}

Ethical permission was received before the study started. This included permission granted by the twins separately and by the twins' parents. Because the participant adolescent twins were students, necessary permits were obtained from the National Education Directorate. Within the framework of the study, the only audio recording was done during the focus group interviews, whereas both audio and video recording conducted during the sessions.

\subsection{Analysis of Data}

For the analysis of the experimental data, the Wilcoxon Signed Ranks Test in the SPSS 22 (IBM Corp., 2013) program was used. As the scores obtained from scales responded by participants did not have a normal distribution, nonparametric techniques were used.

Within the scope of the qualitative part of the study, first, all the data were scrutinized word by word, and the data cleaned by removing expressions or sentences that were not related to the subject. A sentence-by-sentence analysis method was adapted during the analysis process, codes and themes were determined accordingly. It is clear in the literature that credibility, transferability, dependability, and confirmability should be verified through several strategies in qualitative studies (Marshall \& Rossman, 2006). While the data analyzed in this study, the content analysis technique of categorical analysis and emotional orientation analysis were used. For trustworthiness, in-depth semi-structured interview questions were determined and sent to three experts in the 
field of counseling psychology; the experts revised the questions; sufficient time was spent with participants for focus group interviews, and the researchers avoided making personal judgments during detailed transcriptions and analysis. Interpretation of categories by different researchers or assessing categories at different times are other conditions of trustworthiness. Thus, different parts of the data set were sent to three experts in the field and they were asked to analyze them at two different times. The analyses of the researchers and the analyses obtained from the experts compared and it concluded that the content analyses made by the researchers were appropriate.

\section{Results}

\subsection{Quantitative Results}

The descriptive values related to measurements in the experimental group showed in Table 3 below.

Table 3. Descriptive values for pretest and posttest scores for social anxiety in the experimental group

\begin{tabular}{llllll}
\hline & Scores & & $\mathrm{N}$ & $M$ & Ss \\
\hline Experimental group & Pretest & Anxious & 8 & 65.1 & 11.2 \\
& & Avoiding & 8 & 64.5 & 11.1 \\
& \multirow{3}{*}{ Posttest } & Anxious & 8 & 42.7 & 13.1 \\
& & Avoiding & 8 & 43.2 & 10.7 \\
\hline
\end{tabular}

As seen in the table, the mean pretest scores for the anxious dimension of the social anxiety scale for adolescent twins in the experimental group were 65.1, while the mean pretest scores for avoiding were 64.5. The standard deviation was 11.2 for the anxious subscale and 11.1 for the avoiding subscale. The mean posttest scores were 42.7 for the anxious subscale and 43.2 for the avoiding subscale. The standard deviation was 13.1 for the anxious subscale and 10.7 for the avoiding subscale.

The results of the Wilcoxon Signed Ranks Test, which was carried out for testing whether there were significant differences between the pretest and posttest scores of adolescents in the experimental group, gave in Table 4 below.

Table 4. Wilcoxon Signed Ranks test results for comparison of pretest and posttest scores for Liebowitz social anxiety in the experimental group

\begin{tabular}{lllllll}
\hline Scores & Ranks & $\mathrm{N}$ & Rank mean & Rank total & $\mathrm{z}$ & $\mathrm{p}$ \\
\hline Anxious & Negative ranks & 8 & 4.50 & 36 & -2.521 & .012 \\
& Positive ranks & 0 & 0 & 0 & & \\
\multirow{4}{*}{ Avoiding } & No difference & 0 & & & & \\
& Negative ranks & 8 & 4.50 & 36 & -2.521 & .012 \\
& Positive ranks & 0 & 0 & 0 & & \\
& No difference & 0 & & & & \\
\hline
\end{tabular}

As seen in the table, according to the Wilcoxon Signed Ranks Tests, which were conducted to find out whether there were statistically significant differences between the anxiety levels of the participant eight people before and after the program $(\mathrm{z}=-2.521, \mathrm{p}<0.05)$, whose anxiety levels were determined through LSAS before and after the program, the difference in scores was in favor of the negative ranks (initial value), which means that the program had a significant effect in reducing the anxiety levels.

\subsection{Qualitative Results}

The themes that emerged within the scope of the qualitative part of the study gave in Table 5 below. 
Table 5. Themes

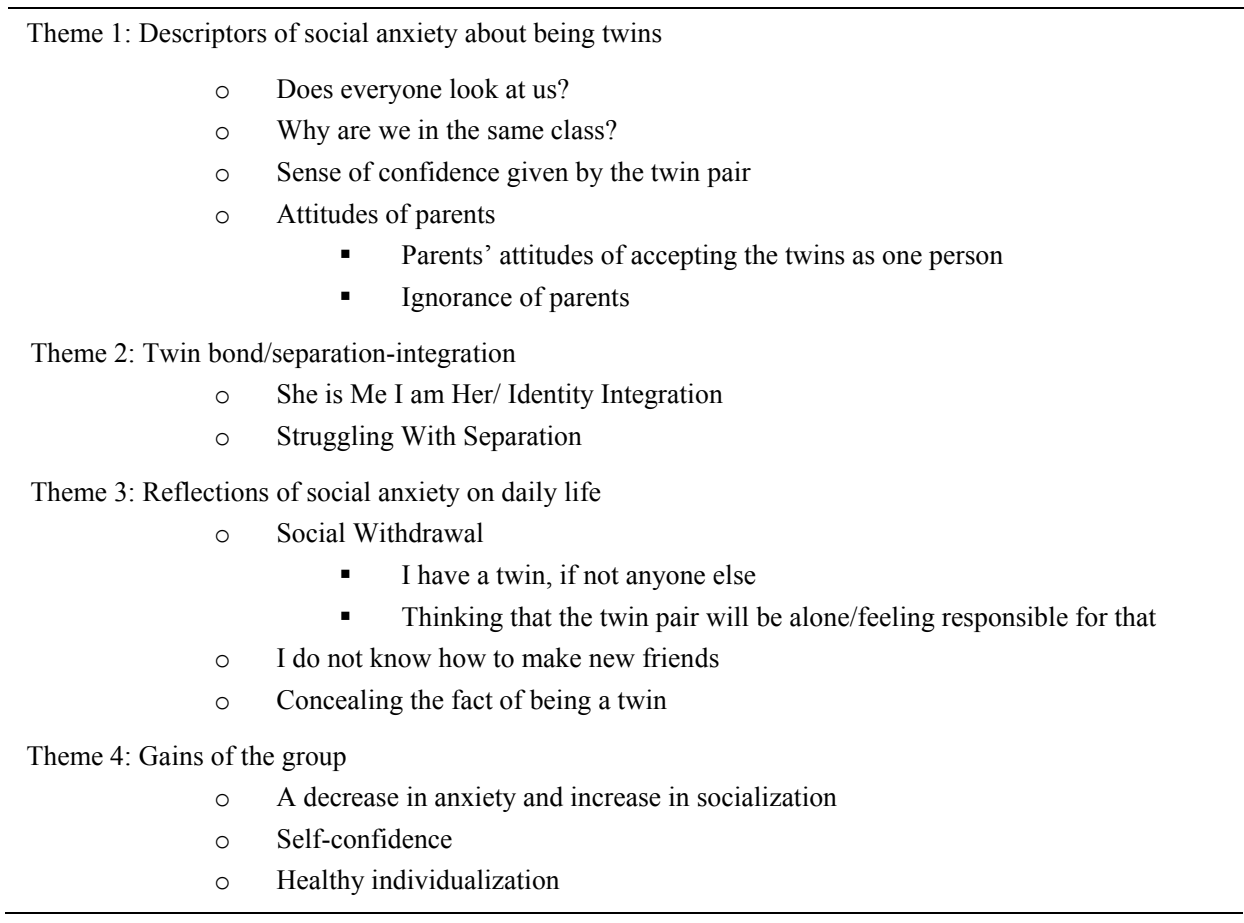

Descriptors of social anxiety about being a twin. This theme reveals the fact that being a twin has different descriptors on social anxiety. While these descriptors may be different from those of singletons, there may also be some similarities. The question of "Does everyone look at us?" was determined to be the first sub-theme. Starting from their early childhood times, twins think that everyone turns head to them when they enter a social environment just because they are twins. The questions they frequently receive when it is understood that they are twins make them feel disturbed in social environments. They think that this also increases their level of anxiety. "I feel that I am in the spotlight, everyone looks at us when I am with my twin pair, and everyone asks us questions such as who was born first or whether we get on well with each other. We receive so many questions that I do not want to enter a new social environment, and I stammer frequently or I avoid answering the questions, I already feel ashamed when I reply to the questions" (Twin 1-A). The question of "Why are we in the same class?" was determined to be the second sub-theme. The twins that are in the same class state that they have difficulty in making new friends when they start their education life. They express that they mostly do not want to make new friends because they do not feel the need for a friend as they have a twin pair in the class. "When we started school, our parents or the teacher did not say anything to us about being in different classes. We have been in the same class ever since I could remember. We have been desk mates almost all the time. I have never wanted to make a new friend because I have always had my best friend with me already" (Twin 2-B). The third sub-theme was determined to be the "sense of confidence given by the twin pair." The participant twins state that the social anxiety that they experience does not disappear completely, but decreases to a certain level if they are with their twin pairs when they enter or have to enter a new social environment. They underline that the presence of their twin pairs helps them feel more comfortable in social environments, whereas their absence increases their level of anxiety. "I feel anxiety to a lesser degree if I am with my twin pair in a social environment, I am very lucky because my twin pair gives me strength and confidence" (Twin 1-B). I even travel on the bus more comfortably if my twin pair is with me; I mostly walk home if I do not have my twin pair with me" (Twin 3-B). The fourth and last sub-theme was "parents' attitudes." The twins state that their parents' attitudes starting from their childhood times affect their level of social anxiety. Two codes were obtained under this sub-theme. The first code is "parents' attitudes of accepting the twins as one person." The twins state that when the parents intentionally or unintentionally behave in a way that accepts the twins as one person, all these behaviors influence the twins' level of social anxiety. Moreover, they express that their parents' attitude to treat the twins equally, not fairly, spurs social anxiety. They explain that especially the parents' efforts to create living quarters for the twins give them the message to live as if they were only one person indeed, and so they do not need to socialize when they are with their twins, whereas they feel anxious when they are not with their twin pairs. "My mother still treats us as if we were only one person. For example, when I ask her for permission to go 
somewhere, she says things like, 'I can let you go if you two go together, you should come back home together, don't leave your twin alone.' I think that this also affected me in a way that I have never tried doing something when I am not with my twin pair. In time, I came to a point that I could not do such a thing even if I wanted to do There is no doubt that the only person responsible for that is not my mother, but I think that she was quite influential about that" (Twin 4-A). Another code that emerged under this sub-theme is "ignorance of parents." The twins tell that their parents had hard times while they were raising children, and so there were many times when their parents could not care about them sufficiently. They go on to say that, the twins had to do parenting each other most of the time, and so they attributed different meanings to themselves and each other. With the burden of the responsibilities taken by the parenting twin, they withdrew from socializing. "Of course, it is to raise twins. I understand my mother. She did not have anyone to help her. My father used to work all the time. had other siblings that my mother had to take care of. Therefore, my mother used to trust me to take care of my pair. I was the one who was playing the role of motherhood. I could not find any time to socialize. I even could play with my friends on the streets. In fact, they also did not want to play with me as I was playing the role of motherhood. Now, I cannot act differently even if I wish to do so. I always feel a heavy burden on my shoulders" (Twin 3-A).

Twin bond/separation-integration. Twins say that they are treated as if they are only one person, not two separate people since birth. They identify that they have similar names and they receive education in the same schools and classes. They emphasize that their parents, relatives, and friends also treat them as one person. This leads to a strong bond between twins, which in turn causes separation and integration problems. The first sub-theme that falls under this theme is "she is me and I am her/identity integration." Twins express that they feel as if they were one person, not two separate people, because of factors such as upbringing and reactions from around. They go on to say that after a certain time, they unconsciously start to prefer similar clothes, behave in similar ways, even display similar personal qualities. One of the participants explains the issue with the words below: "I mostly think that I do not need anybody, but my twin pair. We were together in the same womb. My twin pair has been my best friend since I was born; I have always done everything with my twin. Does my twin want to socialize? S/he can do it with me. Will my twin go somewhere? We can go together" (Twin 1-B). The second sub-theme that falls under this theme is "struggling with separation." Some of the twins say that they are not happy with identity integration, but they cannot complete the separation process successfully. "I can't say that I like being a twin. In fact, I used to like it when I was a kid, but I started to dislike being a twin, as I got older. I have always felt disturbed to have one more me besides me. I tried to make new friends, but unfortunately, I did not know how to socialize. After I had unsuccessful attempts, I lost hope and went back to the beginning. I closed myself to everybody, except for my twin pair. I even closed myself to my twin. Why did I always have to be two but the same person? I said that I was me, but I was always treated as if I were the same person in two different bodies" (Twin 4-B).

Reflections of social anxiety in daily life. The twins underline that being a person with a high level of social anxiety has various aspects that affect their daily life. The first of these reflections is the sub-theme of "social withdrawal." The twins tell that they withdraw from their environment and do not even try to socialize due to a high level of social anxiety. They specifically say that the most important reason for that is their own thought that says, "I have my twin pair, if not anyone else." They think that the presence of their twin pairs makes their lives easier in this process. They say another reason is that they feel if they deal with their social anxiety, then they will make new friends, but they do not want "their twins to feel lonely" because of that. Therefore, they try to find reasons for their problems and they mostly develop ideas, which say that they cannot have better friends than their twins. One of the participants expresses his/her opinions with the words below: "I have tried to socialize with the help of the psychological counselor at my school before. I did some exercises to deal with my anxiety. I resorted to my twin when my friends did not accept me. My twin took the role of cushioning my wounds. When I tried again later, I noticed that I could make new friends. However, this time, my twin started to withdraw. I think, she thought that she was losing me. I tried to include my twin, but she could not do it. This affected me much, as well. Of course, my friends whom I had recently met did not bother themselves about that. In addition, I could not let my twin get lonelier. Therefore, I surrendered and gave up" (Twin 2-A). The second sub-theme is "I do not know how to make new friends." One of the points, which the twins repeatedly emphasize, is that they do not how to socialize. According to them, the reason why they do not know how to socialize is that they came to life accompanied by a friend, they do not need to socialize in a social environment, and that they socialize with their twins all the time. Because of these reasons, twins see other people as a foreigner and they feel that their level of anxiety increases when they enter a social environment, meet new people or make new friends. One of the participants clarifies the issue with the words below: "My mother, father and other siblings always get angry with us or make fun of us. Twins, who understand other twins, right? I already have my twin 
with me, I mean, my best friend. Then, why should I try to make new friends? I already cannot make new friends even if I try doing it. I do not know how to make new friends and even the idea of approaching someone makes my heart beat faster" (Twin 2-A). I was even anxious about being in this group at first. After all, I do not know anybody else apart from my twin. I think I have had only one friend since my childhood times, and it is my twin. I have never tried to make new friends on my own because I do not know how this. Don't you need someone to teach you how to drive? No one has taught me, and I could not learn it by myself as I thought I did not have such a need" (Twin 4-A). The last sub-theme is "concealing the fact of being a twin." The twins tell that they cannot avoid entering a social environment all the time though they do not like it, so they come to a common decision to conceal the fact that they are twins when they have to enter a social environment, and they sometimes say that they are only siblings, whereas they sometimes act as if they did not know each other. They think that they decrease the possibility of attracting attention if they do so. The twins also add that they are happy to be twins, but they do so because they have to. "I was chosen for the high school quiz competition. It held in a big hall and there were many spectators. Before the program started, my twin and I made a deal. We decided to act as if we did not know each other. We dressed in different styles, we made our hair in different styles, and even my twin did not wear glasses on that day. Thus, no one in the other group could understand that we were twins. It was already very very difficult to be included in the program in front of so many people. I did not want anyone to know that I am a twin. However, of course, the presence of my twin was calming for me. I knew that my twin was there to help me in case of fainting or throwing up (Twin 1-B).

Gains of the group. What the participant twins gained after the intervention program revealed in this theme. The first sub-theme here is "decrease in social anxiety and increase in socialization." The group members who specified that the group was effective told that they started to socialize and they did not get anxious in social environments as much as before. The participants express their opinions on the issue with the words below: "I used to walk instead of traveling by bus before. For over two weeks, I have been traveling by bus on my own (Twin 3-B)." "I made a presentation in class for the first time in my life. Not surprisingly, it was too difficult, but I did not faint or throw up (Twin 1-A)." The second sub-theme is "self-confidence." The participants tell that their self-confidence has increased as their social anxiety decreases that they start to do things that used to create social anxiety in them before, or at least they consider the idea of doing activities that cause anxiety. One of the participants says: "I will go to the birthday party of a friend next week. I am very excited, but I believe in myself (Twin 2-B)." "I will also do something that I have wanted to do for years. I think I will join the theatre club. I have not decided for sure, yet. However, I have been thinking of it more often recently (Twin 3-B). The last sub-theme here is "healthy individualization." As the twins' social anxiety decreased, the problem of separation and integration, which is accepted to be one of the major problems that twins experience in life, changed in a way that the twins did not feel obliged to each other and they started to separate. The twins say that they gave up doing most activities together and started to respect each other's individuality. "In the past, the idea of my twins having a boyfriend used to drive me crazy. But now, this idea sounds appealing to me (Twin 3-A)." "We, two, are not one person. We are two different people and of course, we can have different lives. This does not mean that we do not like each other. This only means that we can be different. I respect our decisions even though my twin does not think like me (Twin 4-B).

\section{Discussion}

When the results of the experimental part of this study were examined, it was found that the program is effective in decreasing twins' social anxiety. In fact, a significant difference was observed in favor of negative ranks (initial measurement) between pretest/posttest scores received on the scale by adolescent twins. This situation is valid for both anxious and avoiding subscales. On the other hand, when the results of the qualitative part of the study are examined, four themes emerged. The themes are listed as descriptors of social anxiety about being a twin, twin bond/separation integration, reflections of social anxiety on daily life, and group gains.

While the level of social anxiety of all the twins who participated in the study with their twin pairs was higher than the mean score before the intervention program ( $\mathrm{M}=65.1$ Anxious; $\mathrm{M}=64.5$ Avoiding), the scores decreased after the program ( $\mathrm{M}=42.7$ Anxious; $\mathrm{M}=43.2$ Avoiding). It was found out that after the intervention program, none of the participants met the diagnosis criteria of social anxiety. This finding is supported by both the experimental and qualitative parts of the study. The literature review shows that there is no intervention program aiming at decreasing the social anxiety of twins. However, the study findings comply with the findings of studies that address intervention programs designed for dealing with the social anxiety of singleton individuals. Intervention programs in all these studies were also prepared depending on the cognitive behaviorist approach and these studies' findings show that individuals' social anxiety levels decrease.

In the cognitive model of social anxiety, cognitive processes with disrupted functioning in the individual are 
indicated to be factors sustaining social anxiety (Clark \& McManus, 2002). In general, social anxiety in adolescents results from making new friends, attempting alternative behavior models, and thoughts about rejection in social environments (Leary \& Kowalski, 1995). When considered in this context, the environmental dimension of social anxiety comes to the fore, with studies about the genetics of social anxiety found in the literature (Fyer et al., 1993; Hattema et al. 2005; Kendler et al., 2001; Kendler et al., 1999; Middeldorp et al., 2005). It appears that environmental factors indicated more in the cognitive model of social anxiety. In fact, a person that attributes too much importance to assumptions about what others think with repeated exposure to unavoidable social environments reacts by disrupting social interaction and performance (Leary \& Kowalski, 1995).

When the studies that underline the fact that environmental factors are important in the development of social anxiety are examined, it gets clear that social factors are quite influential on social anxiety (Beck \& Emery, 2015). When the literature is examined, research findings are showing that socialization processes within the family (Bögels et al., 2001; Ingles et al., 2005), inconsistency between parents while raising children and disrupted self-esteem (Dilbaz, 1997), and fear of negative evaluation (Stein et al., 2002) cause social anxiety. Adolescents may experience social anxiety in situations with new social interaction, when making new friends, in situations where alternative behavior models are attempted. In addition, it happens when they think they are rejected in social environments (Leary \& Kowalski, 1995). While all the factors that are valid for singleton individuals are also true for twins, twins' social anxiety levels are affected by some other factors that are only related to being twins. These factors are discussed with the findings of the qualitative part of the study.

The first theme obtained in the study is the descriptors of social anxiety about being a twin. This theme specifies the effect of being a twin with social anxiety on the level of social anxiety. The sub-theme of "Does everyone look at us?" related to twins' attracting attention in society. The point is that twins attract more attention than singletons in society just because they are twins (Ainslie, 1997). It is thought to be an inevitable outcome for twins to attract so much attention in society when it is considered that they get dressed similarly starting from their childhood. Their level of social anxiety increases, even more, when they think that they are in the spotlight. In fact, the cognitive model of social anxiety states that feeling to be in the spotlight increases the level of social anxiety (Stopa \& Clark, 2000). Another sub-theme, "Why are we in the same class?", is about the fact that parents mostly encourage twins to receive education in the same class for various reasons. According to Gleeson, Hay, Johnston, and Theobald (1990), parents want their twins to be in the same class because of the attachment bond and sense of trust between twins as well as the parents' own desires to see twins socialize together. The same parents think that the twins will be unhappy if they receive education in different classes. However, it is stated in the literature that when twins are in the same class, the possibility of a pathological relationship between them is higher (Hay \& Preddy, 2006). They act or make a decision according to each other during decision-making processes (Beauchamp \& Brooks, 2003). They cannot socialize in class or they avoid talking to their classmates, whereas the process of making new friends is damaged as twins want their twin pairs to play or talk only with themselves (Gleeson et. al., 1990). The twins tell that social anxiety does not disappear when they are with their twin pairs, but their presence has a calming effect on them. This theme, which is called, sense of confidence given by the twin pair, points out the attachment and sense of trust between twins. When MZ twins establish a closer relationship between themselves and attach to each other, more strongly, this also has a diminishing effect on anxiety (Segal, 2000). The attachment that twins establish between themselves starting from their childhood brings about trust (Adelman \& Siemon, 1986), and this sense of trust plays a protective role against loneliness (Wilson, 1975) while it affects twins' relationships with other people in their lives (Klein, 2012). This results in a situation where twins feel safe if they are accompanied by their twins in a social environment (van Leeuwen et al, 2005). The last sub-theme that falls under this theme is parents' attitudes and it discussed with the codes of parents' attitudes to evaluate twins as one person and parents' ignorance.

The sub-theme of parents' attitudes, which is accepted to be one of the reasons for social anxiety in literature, also comes out as one of the factors that increase social anxiety in twins. Factors like having twins with premature birth histories and having twins that stay in intensive care units for a long time affect the connection established between mother and baby (Richardson \& Richardson, 1990). Such a connection leads to some troubles that portray the mother as paying more attention to babies considered to have greater requirements for maternal care and having difficulty in socializing with the other baby. What's more, stress and depression experienced by parents in the process of raising twin infants may cause neglecting the babies more (Feldman \& Eidelman, 2004; Yokoyama et al., 1995) and this situation affects twins. Especially MZ twins experience more psychosocial development problems due to parental attitudes toward them (Ainslie, 1997; Lytton et al., 1977; Sandbank, 2006a; Schave \& Ciriello, 1983). Indeed, the studies on social anxiety bring forth that the parents of 
individuals with a high level of social anxiety are likely to have rejective and ignorant parental attitudes (Klonsky et al., 1990). On the other hand, parents are one of the causes of social anxiety that arises from the pressure on the child, which makes the child feel deficient (Pinto-Gouvenia et al., 2006). When the literature examined, low self-esteem is included among general personality traits of individuals with social anxiety (Dilbaz, 1997). There are studies about social fears developing in children due to negative parenting styles, excessive criticism, parental attitudes that embarrass children, being overprotective or isolating the child from social life (Hudson \& Rapee, 2000; Neal \& Edelman, 2003), parental inconsistency (Dilbaz, 1997) and emotional abuse of the child by the parent (Bruce et al., 2012; Simon et al., 2009). Because socialization problems are influential on the development of social anxiety (Leary \& Kowalski, 1995), it stated that parents' behaviors have an impact on social anxiety in twins.

The second theme of the study is Twin bond/separation integration. Twins can sometimes experience identity integration because of parents' attitudes, the relationship between each other, or other social factors. The first sub-theme, "she is me I am her/identity integration" is about twins' perception to be one whole. Parents of twins might be prone to evaluate twins as a whole or as one person due to reasons including the difficulties of raising twin children (Damato, 2004), they mostly dress their twins in similar ways and give them similar names (Robin et al., 1998). All these may have an effect on twins, which makes them feel that they are an integral part of a whole (Stewart, 2000). This situation is thought to cause individualization and socialization problems during the adolescence period (Novotny, 1994). In addition, this leads to a case, which called "dimerization." This concept means that twins' self-representations that show their existence as a separate person merge in a way to make the borders of ego disappear (Joseph, 1961). The individuals that experience dimerization behaves as a whole and possess the same personal qualities instead of existing as a separate person. These individuals do not need anyone else apart from their twins starting from their childhood times. This is also accepted to be one of the reasons for social anxiety specific to twins. The second sub-theme that emerged under this theme is struggling with separation. This results from integration and dimerization. According to a study carried out by Ainslie (1997), twins attach to each other too strongly and have problems of separation because they cannot experience a healthy integration. "They feel deficient in the absence of twins" and this is thought to be closely related to social anxiety.

The third theme of the study is the reflections of social anxiety in daily life. Twins' desire to socialize with only their twin pairs just because of being a twin is also apparent in the sub-theme of social withdrawal. This sub-theme emphasizes twins' withdrawal from social environments and their desire to socialize only with their twin pairs. One of the codes that are included in this sub-theme is I have my twin pair, if not anyone else. Twins that enter a new social environment such as schools want to socialize only with their twin pairs because of their attachment and trust in each other (Gleeson et al., 1990; Klein, 2012). This is because when singletons have a problem with their family members, friends, or people around them, they might not have anyone to support them; however, there is no such possibility for twins, because the existence of twin pair turns out to act as a buffer against social problems (Hay, 2006). Another code is that twins think that their twin pair leave alone when they attempt to deal with social anxiety. This shows that they feel responsible for their twins, which in turn is related to the problem of separation and integration. Twins express that they think their twin pairs' level of anxiety will increase if they make new friends, which is a healthy thing for themselves, indeed; and they say that what their twin pairs feel is important for them. The literature review shows that individuals who develop identity structures experience this. Such type of twins sees their twin pairs as their best friends, and they are the most important support for each other. They imitate their relationships with their twin pairs when they establish a relationship with other people and separation between twins is very hard (Klein, 2003; Schave \& Ciriello, 1983). The third sub-theme is I do not know how to make new friends. This is about the fact that twins cannot socialize from birth and they have their best friends with them, which makes the possibility of new friends impossible. Monozygotic twins are more likely to see their twin pairs as their best friends than dizygotic twins (Foy et al., 2001). According to Hay and Preedy (2006), the twins who are described to be closed couples do not have many friends. This is related to the fact that they do not want to make new friends and they do not know how to make new friends when they want to do so. The last sub-theme under this theme is concealing the fact of being a twin. This sub-theme is related to twins' avoiding social anxiety. Twins conceal the fact that they are twins in social environments because they think that they will not attract attention in this way. The literature review shows that those twins who are not happy with being a twin conceal this fact (Klein, 2003), and this is used by twins to avoid social anxiety.

The last theme of the study, "group gains," is about twins' gains after the social anxiety intervention program. The first sub-theme is a decrease in social anxiety and an increase in socialization after the intervention program. 
There are many studies carried out on this issue which all emphasize that if social anxiety is not cured, it can last until adulthood (see Keller et al., 1992), whereas intervention programs during adolescence decrease social anxiety (Barrett, Dunbar, \& Lycett, 1996; Kendall, 1994). The second sub-theme is self-confidence. This is about an increase in twins' self-confidence to overcome their troubles related to social anxiety. The twins who experience problems of "me and the other" at the point of emotional development may act with no confidence towards themselves as well as others (Cassidy et al., 1996). It told that when their fears and anxieties diminish after the intervention program, their self-confidence increases as well. Finally, twins' expressions that they try to go through the process of separation from their twin pairs healthily and they are in the process of healthy individualization can be interpreted as evidence that shows that twins support each other about dealing with social anxiety.

Consequently, it can state that twins might have a high level of social anxiety because of factors related to being a twin and that the social anxiety intervention program in which the twins participated together was effective in diminishing social anxiety. First, the literature highlights that twins are the group that is prone to social anxiety. The high anxiety scores of the twins in this study also support these findings. This shows that the twins need an intervention program related to social anxiety. Findings obtained from the qualitative part of the study also show that the twins have social anxiety problems due to reasons related to being twins. This shows that all the points addressed while developing the intervention program are supported by the findings obtained from the qualitative part of the research. In addition, one of the findings obtained from the qualitative part, "gains of the groups", shows that the intervention program reduces their social anxiety and increases their socialization, increases their self-confidence, and experiencing a healthier individuation process. This shows that the intervention program has achieved its purpose and that the qualitative and quantitative parts support each other.

\subsection{Limitations and Future Research}

The main limitation of this study is that there was not a control group and a follow-up test did not conduct in the study. This research is an experimental study. According to the utilitarian principle of research in the field of psychological counseling and guidance (Heppner et al., 2008), it is ethically necessary to provide assistance in this field and to carry out beneficial studies within this scope not only for one group but also for everyone. In this study, a pretest-posttest uncontrolled pattern was planned and the study did not consist of a control group without a previously given training. Moreover, it was very difficult to find a sample of twins. As a result, it recommended that future researchers carry out studies about intervention programs dealing with social anxiety prepared for twins by applying it to different samples with experiment, control, and follow-up groups. It recommended that further studies be conducted in the field of individual psychological counseling on intervention programs that aim to help twins use behavioral strategies for coping with social anxiety. It suggested that intervention programs that address coping skills for social anxiety in twins should study with singletons to test the efficacy, whereas it is also necessary to carry out different group studies that compare twins and singletons.

\section{Acknowledgments}

This research is a part of Dr. Şule Baştemur's doctoral dissertation under the supervision of Prof. Dr. Ayşe Esra Aslan at Istanbul University-Cerrahpaşa. Thank you to the twins who participated in the study.

\section{References}

Adelman, M. B., \& Siemon, M. (1986). Communicating the relational shift: Separation among adult twins. American Journal of Psychotherapy, 40(1), 96-109. https://doi.org/10.1176/appi.psychotherapy.1986.40.1.96

Ainslie, R. C. (1997). The psychology of twinship. Jason Aranson Inc.

American Psychiatric Association. (2013). Diagnostic and stastical manual of mental disorders (DSM-V) (5th ed.). American Psychiatric Press. https://doi.org/10.1176/appi.books.9780890425596

Andrews, G., Creamer, M., Crino, R., Hunt, C., Lampe L., \& Page, A. (2003). The treatment of anxiety disorders: Clinician guides and patient manuals. Cambridge University Press. https://doi.org/10.1017/CBO9781316134948

Ateş, C., Öztuna, D., \& Genç, Y. (2009). The use of intraclass correlation coefficient in medical research: Review. Turkiye Klinikleri Journal of Biostatistics, 1(2), 59-64.

Barrett, L., Dunbar, R., \& Lycett, J. (2002). Human evolutionary psychology. Princeton University Press. https://doi.org/10.1007/978-1-137-23550-3 
Beauchamp, H. M., \& Brooks Jr, L. J. (2003). The perceptions, policy, and practice of educating twins: A review. Psychology in the Schools, 40(4), 429-438. https://doi.org/10.1002/pits.10097

Beck, A. T., \& Emery, G. (2015). Anxiety disorders and phobias: A cognitive perspective. Basic Books.

Bögels, S. M., van Oosten, A., Muris, P., \& Smulders, D. (2001). Familial correlates of social anxiety in children and adolescents. Behaviour Research and Therapy, 39(3), 273-287. https://doi.org/10.1016/S0005-7967(00)00005-X

Bruce, L. C., Heimberg, R. G., Blanco, C., Schneier, F. R., \& Liebowitz, M. R. (2012). Childhood maltreatment and social anxiety disorder: Implications for symptom severity and response to pharmacotherapy. Depression and Anxiety, 29(2), 132-139. https://doi.org/10.1002/da.20909

Butler, A. C., Chapman, J. E., Forman, E. M., \& Beck, A. T. (2006). The empirical status of cognitive-behavioral therapy: A review of meta-analyses. Clinical Psychology Review, 26(1), 17-31. https://doi.org/10.1016/j.cpr.2005.07.003

Çakır, S. (2010). The effect of 'overcoming social anxiety program', which is based on the cognitive behaviorist approach, on high school students' level of social anxiety. Unpublished Masters Thesis. Uludağ University, Institute of Educational Sciences, Bursa, Turkey.

Can, A. (2016). Quantitative analaysis with SPSS. Ankara: Pegem.

Cassidy, J., Kirsh, S. J., Scolton, K. L., \& Parke, R. D. (1996). Attachment and representations of peer relationship. Developmental Psychology, 32, 892-904. https://doi.org/10.1037/0012-1649.32.5.892

Clark, D. M., \& McManus, F. (2002). Information processing in social phobia. Biological Psychiatry, 51(1), 92-100. https://doi.org/10.1016/S0006-3223(01)01296-3

Cooper, C. (2004). Twins and multiple births: The essential parenting guide from pregnancy to adulthood. Random House.

Cox, B. J., Pagura, J., Stein, M. B., \& Sareen, J. (2009). The relationship between generalized social phobia and avoidant personality disorder in a national mental health survey. Depression and Anxiety, 26, 354-362. https://doi.org/10.1002/da.20475

Damato, E. G. (2004). Predictors of prenatal attachment in mothers of twins. Journal of Obstetric, Gynecologic, \& Neonatal Nursing, 33(4), 436-445. https://doi.org/10.1177/0884217504266894

Dilbaz, N. (1997). Social fobia. Psikiyatri Dünyası, 1(1), 18-24.

Dilbaz, N. (2001). Validity and reliability of the Liebowitz social anxiety scale (p. 37). National Psychiatry Congress Book, Istanbul, 232.

Dugas, M. J., Ladouceur, R., Léger, E., Freeston, M. H., Langolis, F., Provencher, M. D., \& Boisvert, J. M. (2003). Group cognitive-behavioral therapy for generalized anxiety disorder: Treatment outcome and long-term follow-up. Journal of Consulting and Clinical Psychology, 71(4), 821. https://doi.org/10.1037/0022-006X.71.4.821

Feldman, R., \& Eidelman, A. I. (2004). Parent-infant synchrony and the social-emotional development of triplets. Development Psychology, 40(6), 1133-1147. https://doi.org/10.1037/0012-1649.40.6.1133

Foy, A. K., Vernon, P. A., \& Jang, K. (2001). Examining the dimensions of intimacy in twin and peer relationships. Twin Research and Human Genetics, 4(6), 443-452. https://doi.org/10.1375/twin.4.6.443

Fyer, A. J., Mannuzza, S., Chapman, T. F., Martin, L. Y., \& Klein, D. F. (1993). A direct interview family study of social phobia. Archives of General Psychiatry, 50(4), 286-293. https://doi.org/10.1001/archpsyc.1993.01820160056007

Fyer, A. J., Mannuzza, S., Gallops, M. S., Martin, L. Y., Aaronson, C., Gorman, J. M., ... Klein, D. F. (1990). Familial transmission of simple phobias and fears: A preliminary report. Archives of General Psychiatry, 47(3), 252-256. https://doi.org/10.1001/archpsyc.1990.01810150052009

Gleeson, C., Hay, D. A., Johnston, C. J., \& Theobald, T. M. (1990). Twins in school: An australia-wide program. Acta Geneticae Medicae et Gemellologiae: Twin Research, 39(2), 231-244. https://doi.org/10.1017/S0001566000005468

Hay, D. A. (2006). Adolescent twins and secondary schooling. In A. C. Sandbank (Ed.), Twin and triplet psychology: A professional guide to working with multiple (pp. 119-143). Routhedge. 
Hay, D. A., \& Preedy, P. (2006). Meeting the educational need of multiple birth children. Early Human Development, 82(6), 297-403. https://doi.org/10.1016/j.earlhumdev.2006.03.010

Heimberg, R. G., Brozovich, F. A., \& Rapee, R. M. (2010). A cognitive behavioral model of social anxiety disorder: update and extension. In S. G. Hofmann, \& P. M. DiBartolo (Eds.), Social anxiety: Clinical, developmental, and social perspectives (pp. 95-422). Elsevier Academic Press. https://doi.org/10.1016/B978-0-12-375096-9.00015-8

Heimberg, R. G., Liebowitz, M. R., Hope, D. A., Schneier, F. R., Holt, C. S., Welkowitz, L. A., ... Klein, D. F. (1998). Cognitive behavioral group therapy vs phenelzine therapy for social phobia: 12 -week outcome. Archives of General Psychiatry, 55(12), 1133-1141. https://doi.org/10.1001/archpsyc.55.12.1133

Heimberg, R. G., Salzman, D. G., Holt, C. S., \& Blendell, K. A. (1993). Cognitive-behavioral group treatment for social phobia: Effectiveness at five-year followup. Cognitive Therapy and Research, 17(4), 325-339. https://doi.org/10.1007/BF01177658

Heppner, P. P., Wampold, B. E., \& Kivlighan, D. M. (2008). Research design in counseling. Brooks/Cole Publishing Company.

Hettema, J. M., Prescott, C. A., Myers, J. M., Neale, M. C., \& Kendler, K. S. (2005). The structure of genetic and environmental risk factors for anxiety disorders in men and women. Archives of General Psychiatry, 62(2), 182-189. https://doi.org/10.1001/archpsyc.62.2.182

Hofmann, S. G. (2007). Cognitive factors that maintain social anxiety disorder: A comprehensive model and its treatment implications. Cognitive Behaviour Therapy, 36(4), 193-209. https://doi.org/10.1080/16506070701421313

Hope, D. A., Burns, J. A., Hayes, S. A., Herbert, J. D., \& Warner, M. D. (2010). Automatic thoughts and cognitive restructuring in cognitive behavioral group therapy for social anxiety disorder. Cognitive Therapy and Research, 34(1), 1-12. https://doi.org/10.1007/s10608-007-9147-9.

Hudson, J. L., \& Rapee, R. M. (2000). The origins of social phobia. Behaviour Modification, 24(1), 102-129. https://doi.org/10.1177/0145445500241006

IBM Corp. (2013). IBM SPSS Statistics for Windows (Version 22.0). Armonk, NY: IBM Corp.

Ingles, J. C., Hidalgo, M. D., \& Mendez, X. F. (2005). Interpersonal diffucielts in adolescence: A new self-report measure. European Journal of Psyhcological Assesment, 21(1), 11-22. https://doi.org/10.1027/1015-5759.21.1.11

Joseph, E. D. (1961). The psychology of twins. Journal of the American Psychoanalytic Association, 9(1), 58-166. https://doi.org/10.1177/000306516100900112

Keller, M. B., Lavori, P. W., Wunder, J., Beardslee, W. R., Schwartz, C. E., \& Roth, J. (1992). Chronic course of anxiety disorders in children and adolescents. Journal of the American Academy of Child \& Adolescent Psychiatry, 31(4), 595-599. https://doi.org/10.1097/00004583-199207000-00003

Kendall, P. C. (1994). Treating anxiety disorders in children: Rsults of a randomized clinical trial. Journal of Consulting and Clinical Psychology, 62(1), 100-110. https://doi.org/10.1037/0022-006X.62.1.100

Kendler, K. S., Karkowski, L. M., \& Prescott, C. A. (1999). Fears and phobias: Reliability and heritability. Psychological Medicine, 29(3), 539-553. https://doi.org/10.1017/S0033291799008429

Kendler, K. S., Myers, J., Prescott, C. A., \& Neale, M. C. (2001). The genetic epidemiology of irrational fears and phobias in men. Archives of General Psychiatry, 58(3), 257-265. https://doi.org/10.1001/archpsyc.58.3.257

Kessler, R. C., Berglund, P., Demler, O., Jin, R., Merikangas, K. R., \& Walters, E. E. (2005). Lifetime prevalence and age-of-onset distributions of DSM-IV disorders in the National Comorbidity Survey Replication. Archives of General Psychiatry, 62(6), 593-602. https://doi.org/10.1001/archpsyc.62.6.593

Klein, B. (2003). Psychological profiles of twinship: Not all twins are alike. Praeger.

Klein, B. (2012). Alone in the mirror: Twins in therapy. Routledge Taylor \& rancis. https://doi.org/10.4324/9780203124178

Klonsky, B. G., Dutton, D. L., \& Liebel, C. N. (1990). Developmental antecedents of private self-consciousness, public self-consciousness and social anxiety. Genetic, Social, and General Psychology Monographs, 116(3), 273-297. 
Krueger, R. A. (1994). Focus groups: A practical guide for applied research. Sage

Leary, M. R., \& Kowalski, R. M. (1995). Social anxiety. Guilford.

Lytton, H. (1980). Parent-child interaction: The socialization process observed in twin and singleton families. Plenum Press. https://doi.org/10.1007/978-1-4899-0459-1

Lytton, H., Conway, D., \& Sauve, R. (1977). The impact of twinship on parent-child interaction. Journal of Personality and Social Psychology, 35(2), 97. https://doi.org/10.1037/0022-3514.35.2.97

Mannuzza, S., Schneier, F. R., Chapman, T. F., Liebowitz, M. R., Klein, D. F., \& Fyer, A. J., (1995). Generalized social phobia: Reliability and validity. Archives of Genetic Psychiatry, 52(3), 230-237. https://doi.org/10.1001/archpsyc.1995.03950150062011

Marshall, C., \& Rossman, G. B. (2006). Designing qualitative research. Sage.

McDougall, G. J. (1999). Cognitive interventions among older adults. Annual Review of Nursing Research, 17(1), 219-240. https://doi.org/10.1891/0739-6686.17.1.219

Middeldorp, C. M., Birley, A. J., Cath, D. C., Gillespie, N. A., Willemsen, G., Statham, D. J., ... Boomsma, D. I. (2005). Familial clustering of major depression and anxiety disorders in Australian and Dutch twins and siblings. Twin Research and Human Genetics, 8(6), 609-615. https://doi.org/10.1375/twin.8.6.609.

Mörtberg, E., Karlsson, A., Fyring, C., \& Sundin, Ö. (2006). Intensive cognitive-behavioral group treatment (CBGT) of social phobia: a randomized controlled study. Journal of Anxiety Disorders, 20(5), 646-660. https://doi.org/10.1016/j.janxdis.2005.07.005.

Neal, J. A., \& Edelmann, R. J. (2003). The etiology of social phobia: Toward a developmental profile. Clinical Psychology Review, 23(6), 761-786. https://doi.org/10.1016/S0272-7358(03)00076-X.

Novotny, P. P. (1994). The joy of twins and other multiple births: Having, raising, and loving babies who arrive in groups. Crown Publishers.

Pinto-Gouveia, J., Castilho, P., Galhardo, A., \& Cunha, M. (2006). Early maladaptive schemas and social phobia. Cognitive Therapy and Research, 30(5), 571-584. https://doi.org/10.1007/s10608-006-9027-8.

Rapee, R. M., \& Heimberg, R. G. (1997). A cognitive-behavioral model of anxiety in social phobia. Behaviour Research and Therapy, 35(8), 741-756. https://doi.org/10.1016/S0005-7967(97)00022-3

Rheingold, A. A., Herbert, J. D., \& Franklin, M. E. (2003). Cognitive bias in adolescents with social anxiety disorder. Cognitive Therapy and Research, 27(6), 639-655. https://doi.org/10.1023/A:1026399627766

Richardson, R. W., \& Richardson, L. A. (1990). Birth order and you. International Self-Cousil Press.

Robin, M., Le Maner - Idrissi, G., \& Corroyer, D. (1998). Mothers' representations of their 13 - month - old twins and child - raising attitudes. Infant Mental Health Journal: Official Publication of the World Association for Infant Mental Health, 19(1), 1-19. https://doi.org/10.1002/(SICI)1097-0355(199821)19:1<1::AID-IMHJ1>3.0.CO;2-T.

Sandbank, A. C. (2006a). Introduction: The importance of understanding the psychology of twin and triplet relationship. In A. C. Sandbank (Ed.), Twin and triplet psychology: A professional guide to working with multiple (pp. 1-7). Routhedge.

Sandbank, A. C. (2006b). Personality, identity and familiy relationship. In A. C. Sandbank (Ed.), Twin and triplet psychology: A professional guide to working with multiple (pp. 167-186). Routhedge.

Sayan, A. (2005). The effect of 'coping with social anxiety programme' on the social anxiety and depression levels of students. Unpublished Masters Thesis, Gazi University, Institute of Educational Science, Ankara, Turkey.

Schave, B., \& Ciriello, J. (1983). Identity and intimacy in twins. Preager.

Segal, N. (2000). Enwined lives: Twins and what they tell us about human behavior. Penguin Putnam.

Sertelin-Mercan, Ç. (2007). The effect of social skills education program integrated with cognitive behavioral approach on social anxiety level of adolescents. Unpublished PhD Thesis, Istanbul University, Institute of Educational Science, Istanbul, Turkey.

Simon, N. M., Herlands, N. N., Marks, E. H., Mancini, C., Letamendi, A., Li, Z., ... Stein, M. B. (2009). Childhood maltreatment linked to greater symptom severity and poorer quality of life and function in social anxiety disorder. Depression and Anxiety, 26(11), 1027-1032. https://doi.org/10.1111/cpsp.12303 
Smith, B., Fowler, D. G., Freeman, D., Bebbington, P., Bashforth, H., Garety, P., ... Kuipers, E. (2006). Emotion and psychosis: Links between depression, self-esteem, negative schematic beliefs and delusions and hallucinations. Schizophrenia Research, 86(1), 181-188. https://doi.org/10.1016/j.schres.2006.06.018

Stein, M. B., \& Chavira, D. A. (1998). Subtypes of social phobia and comorbidity with depression and other anxiety disorders. Journal of Affective Disorders, 50, 11-16. https://doi.org/10.1016/S0165-0327(98)00092-5

Stein, M. B., Jang, K. L., \& Livesley, W. J. (2002). Heritability of social anxiety-related concerns and personality characteristics: A twin study. The Journal of Nervous and Mental Disease, 190(4), 219-224. https://doi.org/10.1097/00005053-200204000-00002

Stewart, E. (2000). Towards the social analysis of twinship. British Journal of Sociology, 51(4), 719-737. https://doi.org/10.1080/00071310020015343

Stopa, L., \& Clark, D. M. (2000). Social phobia and interpretation of social events. Behaviour Research and Therapy, 38(3), 273-283. https://doi.org/10.1016/S0005-7967(99)00043-1.

Şimşek, H. (2011). The effects of 'social skills training program' on level of social anxiety. Unpublished Masters Thesis, Dokuz Eylül University, Institute of Educational Science, Izmir, Turkey.

Torgersen, S. (1979). The nature and origin of common phobic fears. The British Journal of Psychiatry, 134(4), 343-351. https://doi.org/10.1192/bjp.134.4.343

Torvik, F. A., Welander-Vatn, A., Ystrom, E., Knudsen, G. P., Czajkowski, N., Kendler, K. S., \& Reichborn-Kjennerud, T. (2016). Longitudinal associations between social anxiety disorder and avoidant personality disorder: A twin study. Journal of Abnormal Psychology, 125(1), 114. https://doi.org/10.1037/abn0000124.

Turner, S. M., Beidel, D. C., \& Townsley, R. M. (1992). Social phobia: A comparison of specific and generalized subtypes and avoidant personality disorder. Journal of Abnormal Psychology, 101, 326-331. https://doi.org/10.1037/0021-843X.101.2.326

Van Dam-Baggen, R., \& Kraaimaat, F. (2000). Group social skills training or cognitive group therapy as the clinical treatment of choice for generalized social phobia? Journal of Anxiety Disorders, 14(5), 437-451. https://doi.org/10.1016/S0887-6185(00)00038-4.

Van Leeuwen, M., Van Den Berg, S. M., van Beijsterveldt, T. C., \& Boomsma, D. I. (2005). Effects of twin separation in primary school. Twin Research and Human Genetics, 8(04), 384-391. https://doi.org/10.1375/twin.8.4.384

Warren, S. L., Schmitz, S., \& Emde, R. N. (1999). Behavioral genetic analyses of self-reported anxiety at 7 years of age. Journal of the American Academy of Child \& Adolescent Psychiatry, 38(11), 1403-1408. https://doi.org/10.1097/00004583-199911000-00015

Wilson, R. S. (1975). Twins: Patterns of cognitive development as measured on the wechsler preschool and primary scale of intelligence. Developmental Psychology, 11(2), 126. https://doi.org/10.1037/h0076458

Yokoyama, Y., Shimizu, T., \& Hayakawa, K. (1995). Maternal partial attachment for one of apair of twins and the influence of child caring environments. Nippon-Koshu Eisei-Zasshi, 42(2), 104-112.

\section{Copyrights}

Copyright for this article is retained by the author, with first publication rights granted to the journal.

This is an open-access article distributed under the terms and conditions of the Creative Commons Attribution license (http://creativecommons.org/licenses/by/4.0/). 